\title{
Characterisation of the Colour Fraction of Pedro Ximenez Andalusian Sweet Wines
}

\author{
M.P. Serratosa, A. Lopez-Toledano, M. Medina and J. Merida* \\ Department of Agricultural Chemistry, Faculty of Sciences, University of Cordoba, Edificio Marie Curie, Campus de Rabanales, \\ E-14014, Cordoba, Spain
}

Submitted for publication: February 2011

Accepted for publication: February 2011

Key words: Sweet wines, Pedro Ximenez, browning, CIELab

\begin{abstract}
Changes in colour fraction of commercially bottled Pedro Ximenez sweet wines, unaged and oxidatively aged in American oak casks and mostly produced in the Montilla-Moriles and Jerez-Xérès-Sherry Designations of Origin (Spain), have been studied. The total tannin content and the total polyphenol content (A280) increased with increased aging time, a trend clearly observed in the Jerez wines. Browning, as measured by the absorbance at $420 \mathrm{~nm}$, differed markedly between unaged and aged wines. Aged wines showed an increase in browning with time and an increase in high molecular weight browning compounds, most probably Maillard compounds. Colour measurements based on the CIELab system showed a gradual decrease in hue and lightness with ageing.
\end{abstract}

\section{INTRODUCTION}

Among the European sweet wines, with the Porto wines probably being the better known wines on account of their special production process, the Pedro Ximenez wines made in southern Spain have lately become more popular. Pedro Ximenez sweet wines are produced from Pedro Ximenez grapes that have been sun-dried. Grapes are harvested at approximately 13 to $14^{\circ}$ Baumé and are dried on long plastic strips with mild slopes facing south. The grapes are turned periodically to ensure uniform drying. At present, most Pedro Ximenez raisins used to produce these sweet wines in Spain are grown in the Montilla-Moriles D.O. region, where the special climatic conditions required to sun-dry grapes in the traditional manner prevail. Such conditions include high temperatures in August and very low relative humidity. In this month the mean high in the region was $35.9^{\circ} \mathrm{C}$ over the past 30 years, with temperatures easily reaching 45 to $50^{\circ} \mathrm{C}$ in the sun in the middle of day. The mean relative humidity for the same period was $46 \%$ (data reported by AEMET, Spanish Government). In these conditions, and depending on the particular climatic conditions of the year, the raisining process takes five to seven days, but it can be as long as 10 days under specially unfavourable circumstances. Irrespective of origin, must from Pedro Ximenez raisin is vinified and aged in other places, such as the Jerez-Xérès-Sherry D.O., where the climate is not as hot and more humid (the mean high and relative humidity in August for the previous 30 years were $33.1^{\circ} \mathrm{C}$ and $56 \%$, respectively); these are climatic conditions under which, being difficult in these climatic conditions to obtain a satisfactory raisining without fungi growth on the grape.

Sun drying increases the brown colour in grapes (Karadeniz et al., 2000) and reduces hue and lightness, resulting in an increasing chroma (Serratosa et al., 2008). These colour changes are a result of the formation of brown pigments from phenolic compounds effected by polyphenol oxidase activity (Gunata et al., 1987) and other non-enzymatic reactions (Ramshaw \& Hardy, 1969; Karadeniz et al., 2000). In addition, the exposure of berries to high temperatures (above $50^{\circ} \mathrm{C}$ ) can result in the formation of melanoidins, which are polymers that typically appear during later stages of the Maillard reaction (RiveroPerez et al., 2002).

Once collected, raisins are crushed and pressed to obtain musts with a high sugar concentration and dark brown hues that are partially fermented to 1.5 to $2.0 \%(\mathrm{v} / \mathrm{v})$ ethanol and then fortified to 15 to $22 \%$ by addition of wine alcohol. The young sweet wines thus obtained are subjected to dynamic oxidative aging by means of the so-called "criaderas and solera" system. Such a system consists of several stacked rows of American oak casks containing wine aged for a variable length of time increasing from the bottom to the top., A volume of the younger wine periodically is transferred to the next row containing the older wine (Casas, 1985)., The term "vintage" therefore does not apply to this type of wine, the aging of which should simply be designated in terms of aging time or residence time in the cellar.

Oxidative aging in wood is a complex process that leads to multiple changes in wine. On the one hand, it induces major oxidation reactions of phenolic compounds in wine (Amerine \& Winkler, 1944; Singleton, 1987), particularly those involving the flavan-3-ol derivatives, which have proved to be effective substrates for several browning reactions (Simpson, 1982; Merida et al., 2006). In addition, wine in contact with cask wood for a long time can extract ellagitannins and a variety of other compounds from it (Ortega-Heras et al., 2004). Nevertheless, 
the specific nature of these compounds differs markedly with wood type and treatment, and also with the average temperature during the aging process (Rous \& Alderson, 1983; Cadahia et al., 2001). On the other hand, some volatile compounds present in grapes have been found to disappear partially during aging in wood casks (Escalona et al., 2002). By contrast, some authors (Chaves et al., 2007) have found wine to be enriched with fruity, fatty, floral and balsamic notes during oxidative aging in wood containers.

The purpose of this work was to characterise the colour fraction of commercial Pedro Ximenez sweet wines, both young and aged for variable lengths time in different cellars of the two Designations of Origin producing most of this type of wine in Spain (Montilla-Moriles and Jerez-Xérès Sherry). The main objective of this characterisation is to relate their colour characteristics to the length of their oxidative aging and/or the temperature and moisture conditions prevailing during the aging in the two designations of origin mentioned above, with a view to future standardisation of the different qualities, thereby facilitating easier identification by consumers.

\section{MATERIALS AND METHODS Samples}

A total of $84(28 \times 3)$ samples of commercial Pedro Ximenez sweet wines obtained from ten different winemakers in the Montilla-Moriles D.O. $(14 \times 3$ bottles $)$ and 12 from others in the Jerez-Xérès-Sherry D.O. were subjected to triplicate analyses (also $14 \times 3$ bottles). The wines were different in oxidative aging time as stated on the product labels and by information of the cellars themselves (from young to 25 years old).

\section{Reducing sugars and $\mathrm{pH}$}

These two parameters were determined according to the EEC official methods as described in Regulation 2676/1990 (EEC, 1990).

\section{Tannin index}

A volume of $2 \mathrm{~mL}$ of 1:50 diluted wine was supplied with $6 \mathrm{~mL}$ of $12 \mathrm{~N} \mathrm{HCl}$ in a vessel that was tightly closed and protected from light prior to heating in a water bath for $30 \mathrm{~min}$. Following rapid cooling, the wine was supplied with $1 \mathrm{~mL}$ of ethanol and homogenised, and the resulting absorbance at $550 \mathrm{~nm}$ was measured. The measured absorbance value was then reduced by subtracting the result of a blank test with no sample or heating (Ribereau-Gayon et al., 1998).

\section{UV-visible spectra and colour measurements}

UV-Vis spectra were obtained in the range 250-780 nm using water as reference. The spectrum in the UV zone and absorbances at $280 \mathrm{~nm}$ were measured after dilution at 1:10 and A420 was considered as browning index. Colour analyses were carried out following C.I.E. recommendations (CIE, 2004) and using the visible spectrum obtained from 380 to $780 \mathrm{~nm}$ (Perkin Elmer Lambda 25 model). In this study, the CIELab uniform space colorimetric parameters that were considered were the rectangular coordinate $\mathrm{L}^{*}{ }_{\mathrm{ab}}$ (black-white component, lightness) and the cylindrical coordinate $h_{\mathrm{ab}}$ (hue angle). These parameters were measured using the CIE (CIE, 2004), Standard Observer ( $10^{\circ}$ visual field) and the CIE standard illuminant D65 as references.

All spectrophotometric measurements were obtained after filtration of the samples through a filter of HA- $0.45 \mu \mathrm{m}$ pore size (millipore) and using a Beckman spectrophotometer, DU 600 model, on $10 \mathrm{~mm}$ path length for the absorbances at 280 and $420 \mathrm{~nm}$.

\section{Dialysis}

Musts were dialysed using cellulose dialysis tubing (SigmaAldrich) that retained molecules of a size $\geq 12000$ Da. About $15 \mathrm{~mL}$ of must was put into the dialysis tubing and it was placed in a vessel with $1 \mathrm{~L}$ of water. This solution was maintained at $4^{\circ} \mathrm{C}$ with stirring for $12 \mathrm{~h}$, followed by a replacement of the water surrounding the dialysis tubing. This procedure was repeated six times. The volume of must that remained in the dialysis tubing was diluted to $25 \mathrm{~mL}$ with distilled water and the solution was named the dialysed fraction.

\section{Statistical procedures}

Multiple comparison procedure of means, variance analyses (ANOVA) and discriminant analyses (DA) were performed on the replicated samples by using the Statgraphics Statistical Computer Package (Statistical Graphics Corp. v 5.0).

\section{RESULTS AND DISCUSSION}

Pedro Ximenez wines are naturally sweet and have a variably strong ebony colour with iodine-like iridescences and a highly dense visual appearance. All possess an extremely rich aroma with a prevalence of sweet notes of dried fruits (raisins, figs and dates), accompanied by honey, syrup, and fruit compote notes, in addition to toasted (coffee, bitter chocolate, cocoa) and liquorice notes that grow in strength with aging. Based on information from the two Designations of Origin that produce these wines in Spain, they possess a variable alcohol content (15 to $22 \%$ ) and total acidity ( 3 to $5 \mathrm{~g} / \mathrm{L}$ as tartaric acid), a volatile acidity lower than $0.8 \mathrm{~g} / \mathrm{L}$ as acetic acid, and a sugar content ranging from 180 to $500 \mathrm{~g} / \mathrm{L}$.

For this study, bottled wines from various winemakers in the Montilla-Moriles and Jerez-Xérès-Sherry Designations of Origin that had been aged for the specific times and contained the proportions of alcohol given in Table 1, as stated on their labels or communicated by their producers, were obtained. As can be seen, most of the wines were five years old, although the samples from the Montilla-Moriles D.O. included three samples of unaged wines and two of wines aged for a very long time (25 years).

Fig. 1 shows, in a box-and-whisker plot, the maxima, minima, means and ranges of variation, as well as the homogeneous groups, of the $\mathrm{pH}$ (a) and reducing sugar contents (b) of the studied wines. As can be seen, $\mathrm{pH}$ ranged widely (from 3.54 to 4.60 ) and exhibited no correlation with wine age. Based on the results for the wines from the Jerez-Xérès-Sherry D.O., three different groups, namely 3.5 to 3.7 (cellars no. 3, 7 and 9), 4.0 to 4.3 (nos. 2, 4, 6 and 11) and 4.4 to 4.6 (all others) could be established. None of the wines from the Montilla-Moriles D.O. had a $\mathrm{pH}<3.7$ and their $\mathrm{pH}$ showed a higher dispersion. The reducing sugar contents also showed wide variability among the wines (from 257 to $491 \mathrm{~g} / \mathrm{L}$ ), which also exhibited no apparent relationship to the production zone of wine or aging 
time. Therefore, taking into account both acidity and sugars, the balance between sweet and acid flavours in the wines was variable and not dependent on the aging time. In any case, the wines from the Jerez-Xérès-Sherry D.O. were more uniform in this respect, as reflected in tighter clustering in Fig. 1.

Tannins are highly astringent and bitter polyphenol compounds grouped in a series of substances of mainly two types. On the one hand, some tannins are condensed compounds of the flavan-3-ol derivatives that are present in grapes in polymeric forms of greater or lesser complexity. They can be classified according to location in grape skin (Glories \& Saucier, 2000). On the other hand, ellagitannins constitute the major components in the hydrolysable tannin group (Masson et al., 1996), although some authors have also noted the presence of gallotannins in this group (Viriot et al., 1994). Fig. 2 shows in a box-and-whisker plot the maxima, minima, means and ranges of variation of the total tannin index of the wines (measured as absorbance at $550 \mathrm{~nm}$ ). As can be seen, the wines from the Jerez-Xérès-Sherry D.O. exhibited an increase in tannins with aging, as reflected in their mean values $(0.958$ and 1.097 for the five- and ten-year-old wines), minima (0.711 and 0.949, respectively), maxima (1.12 and 1.22) and homogeneous groups $(p<0.05)$. The Montilla-Moriles wines exhibited mean values of $0.989,0.940$ and 1.20 for the five-, ten- and twenty-five-yearold wines, respectively. Such values, however, showed high dispersion, mainly in the five-year-old wines that ranged from 0.568 (lowest) to 1.28 (highest), and they were abnormally high for the unaged wines. Therefore, the homogeneous groups only revealed significant differences between the oldest wines (25 years) and the group formed by those aged for five to ten years. The increase in tannin levels can be ascribed to extraction from the wood as wine ages and also to the concentration effect resulting from evaporation of water through the casks, which is industrially estimated to be about $8 \%$ in volume each

a)

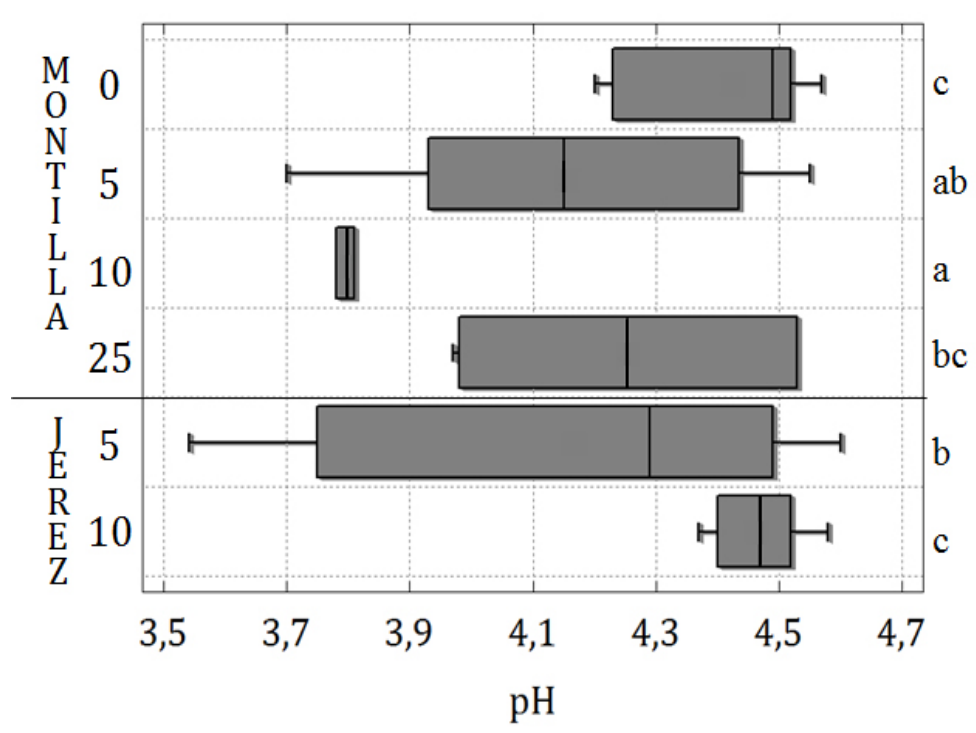

b)

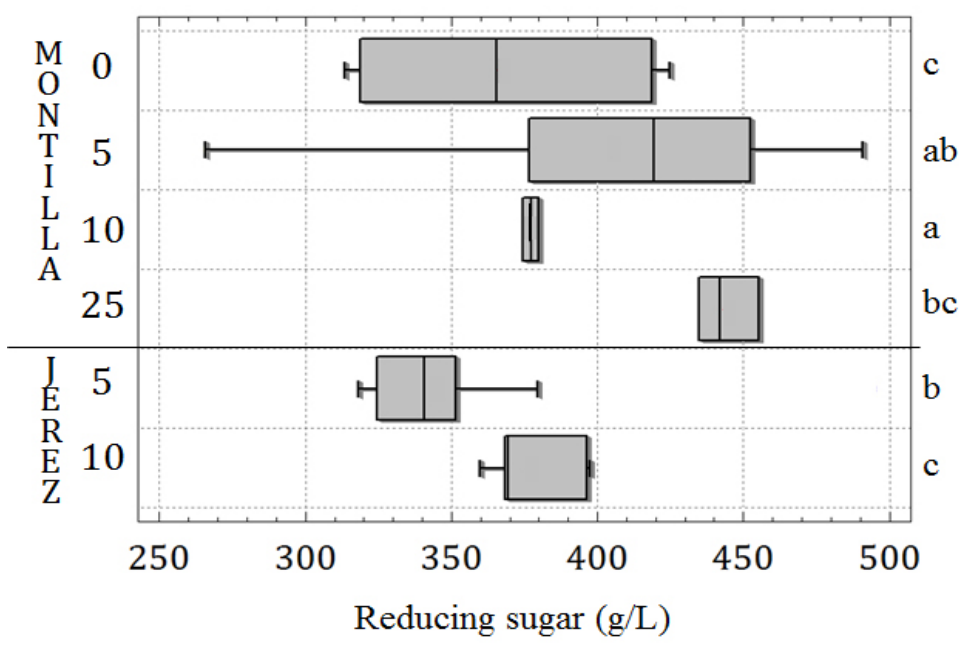

FIGURE 1

Box-and-whisker plot of the $\mathrm{pH}$ (a) and reducing sugar content $(\mathrm{g} / \mathrm{L}$ ) (b) of the unaged and aged Pedro Ximenez sweet wines from Montilla-Moriles and Jerez-Xerez-Sherry D.O. and their statistically homogeneous groups. 
year (Ortega et al., 2003). Although the type of wood used in both Designations of Origin is the same (American oak), the poorer discrimination and/or high dispersion in the wines from Montilla-Moriles may have resulted from the presence of other factors altering the extraction of tannins to an extent dependent on the particular winemaking practices used in each D.O. and by each individual winemaker. Thus, Rous and Alderson (1983) found tannin extraction to decrease when casks are used year after year. Extraction is also known to decrease with increasing surface/volume ratio of the cask (Kadim \& Mannheim, 1999) and with decreasing surface area of medullary beams in each wood stave (Feuillat \& Keller, 1997). In addition, hydrolysable tanning levels can also decrease through the effect of polymerisation and condensation reactions during oxidative aging of wine in wood casks (Gomez-Cordoves \& GonzalezSan Jose, 1995; Fernandez de Simon et al., 1996) leading to precipitation of high-molecular weight compounds in them.

Fig. 3 shows the maximum, minimum and mean values, and range of variation, of the total polyphenol index for the studied wines; it measured as absorbance at $280 \mathrm{~nm}$. This index increased significantly $(p<0.05)$ with aging in the bottles from both Designations of Origin, with mean values of 37.2, 77.1, 62.6 and 122.7 au for the under one-, five-, ten- and twentyfive- year-old wines from Montilla-Moriles and 63.2 and 139 au for the five- and ten-year-old wines from Jerez-Xérès-Sherry. The increase can largely be ascribed to extraction of these compounds from oak wood and their concentration through water loss during aging, both commented on above. In addition, phenol compounds undergo slow oxidation, condensation and/ or polymerisation reactions via non-enzymatic pathways that can lead to the formation of other compounds with a different absorption coefficient at the used wavelength. These factors can have a different influence depending on the particular environmental conditions of each cellar (particularly the prevailing temperature and moisture, and some chemical factors including $\mathrm{pH}$ and metal contents in the wine). This may explain why some samples exhibited a high dispersion in $A 280$ (39.0 and 151.2 as extremes in the five-year-old wine from MontillaMoriles, or 68.5 and 257.6 in the ten-year-old wine from JerezXérès-Sherry).

Fig. 4 shows the ranges of variation of $A 420$ as a measure of browning in the studied wines. As can be seen, there were

TABLE 1

Aging time and alcohol content of the studied wines.

\begin{tabular}{|c|c|c|c|c|c|c|c|c|c|c|c|c|c|c|}
\hline \multicolumn{15}{|c|}{ Montilla-Moriles D.O. } \\
\hline Winemaker & 1 & \multicolumn{3}{|c|}{2} & \multicolumn{2}{|c|}{3} & 4 & 5 & \multicolumn{2}{|c|}{6} & 7 & 8 & 9 & 10 \\
\hline Aging time (yr) & 5 & 5 & 5 & 0 & 5 & 0 & 10 & 25 & 5 & 25 & 5 & 5 & 5 & 0 \\
\hline$\%$ ethanol (v/v) & 15 & 15 & 15 & 15 & 16 & 17 & 16 & 16 & 15 & 15 & 15 & 15 & 15 & 17 \\
\hline \multicolumn{15}{|c|}{ Jerez-Xérès-Sherry D.O. } \\
\hline Winemaker & 1 & 2 & 3 & 4 & 5 & 6 & 7 & \multicolumn{2}{|c|}{8} & \multicolumn{2}{|c|}{9} & 10 & 11 & 12 \\
\hline Aging time (yr) & 5 & 5 & 5 & 5 & 5 & 5 & 5 & 5 & 10 & 5 & 10 & 5 & 5 & 5 \\
\hline$\%$ ethanol (v/v) & 16 & 19 & 18 & 17.5 & 15.5 & 17 & 17 & 17.5 & 17.5 & 18 & 18 & 17.5 & 17 & 18 \\
\hline
\end{tabular}

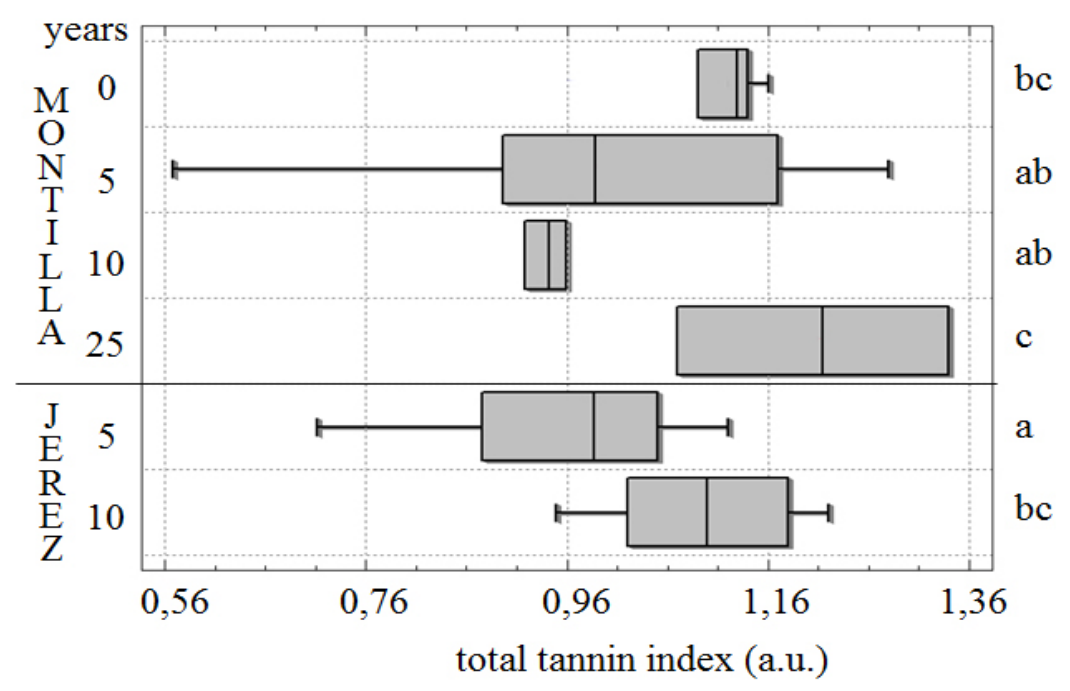

FIGURE 2

Box-and-whisker plot of the total tannin index values (a.u.) in the studied wines and their statistically homogeneous groups. 


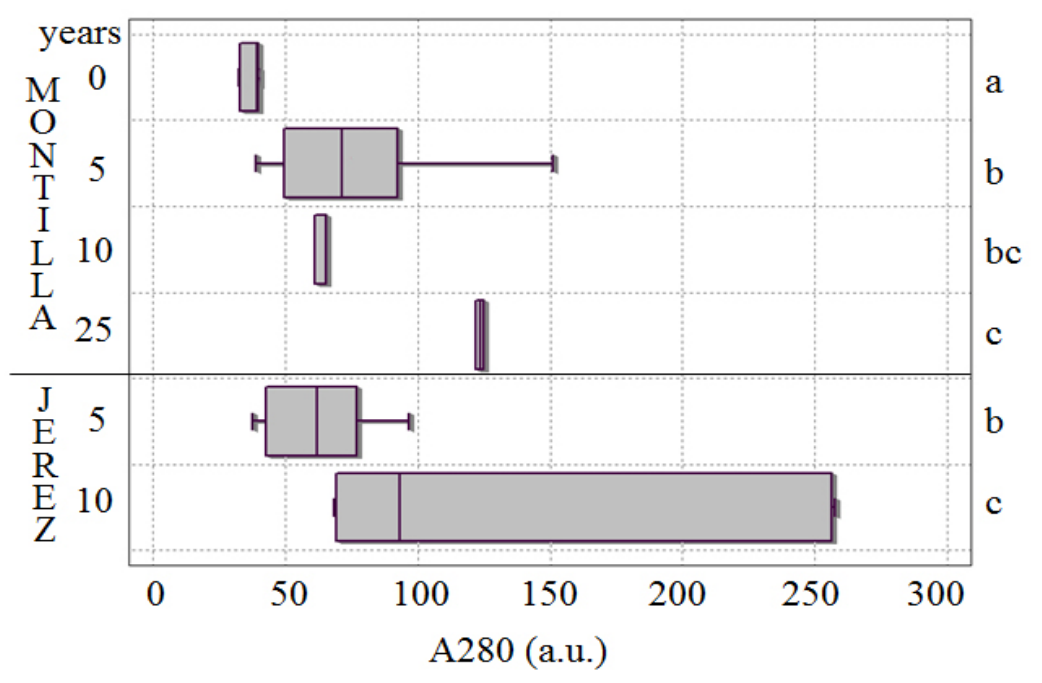

FIGURE 3

Box-and-whisker plot of the absorbance at $280 \mathrm{~nm}$ values (a.u.) in the studied wines and their statistically homogeneous groups.

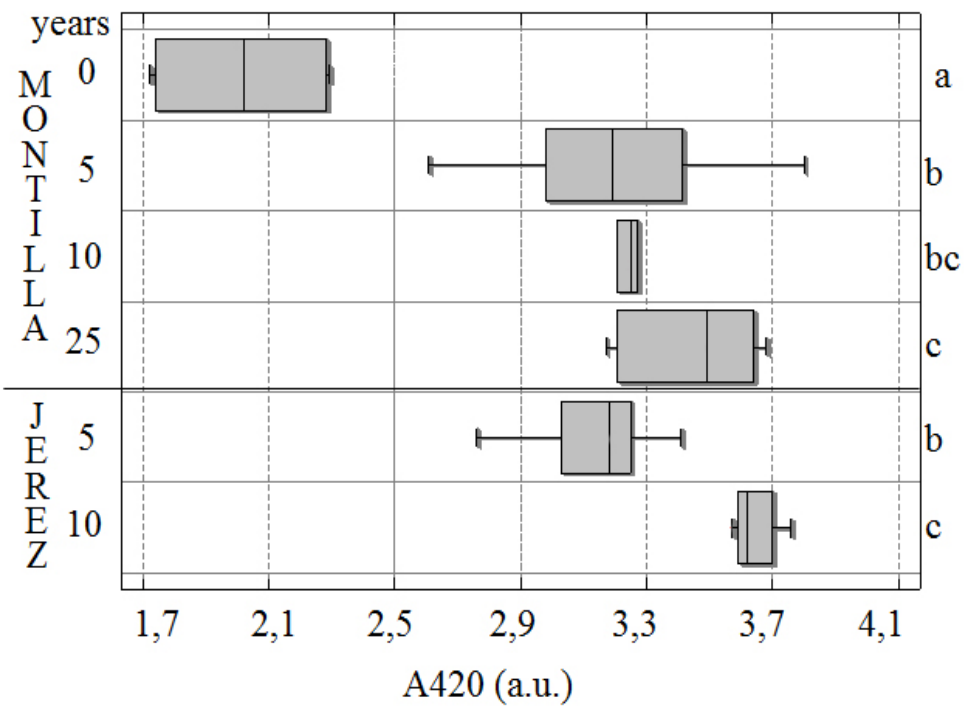

FIGURE 4

Box-and-whisker plot of the absorbance at $420 \mathrm{~nm}$ values (a.u.) in the studied wines and their statistically homogeneous groups.

significant differences between aged and unaged wines (the latter of which were from the Montilla-Moriles D.O.), with mean $A 420$ values of 3.18 to 3.57 and 2.01 au, respectively. Oxidatively aged wines are known to produce brown polymers via several reactions involving phenolic compounds (particularly flavanols). Thus, the oxidation of phenols produces quinones polymerised to a variable degree in a pathway that is catalysed by metals such as $\mathrm{Fe}$ and $\mathrm{Cu}$ to an extent dependent on their concentration in the wine (Oszmianski et al., 1985; Clark \& Scollary, 2002, 2003; Es-Safi et al., 2003;). In addition, the condensation of flavanols with glyoxylic acid (an oxidation product of tartaric acid) gives browning compounds (Es-Safi et al., 2000; Clark et al., 2003; Lopez-Toledano et al., 2004). Finally, direct condensation of phenols with acetaldehyde produced by yeasts during the fermentation step gives brown oligomers (Fulcrand et al., 1996; Saucier et al., 1997; Es-Safi et al., 2000; Merida et al., 2006), although this pathway can hardly have affected the studied wines as they underwent little or no partial fermentation. The fie- and ten-year-old wines from the Jerez-Xérès-Sherry D.O. differed significantly in their degree of browning (their A420 mean values were 3.16 and 3.57 au, respectively). The corresponding values for unaged five-, tenand twenty-five-year-old wines from the Montilla-Moriles D.O. were 2.01, 3.18, 3.24 and 3.44, respectively. However, no significant differences were found between the wines aged for five and ten years, again as a result of the dispersion in the data of commercial wines from this Designation of Origin.

Colour characteristics in the studied wines were measured in terms of the CIELab coordinates. Figs. 5 and 6 show the hue angle $\left(h_{\mathrm{ab}}\right)$ and lightness $\left(L_{\mathrm{ab}}^{*}\right)$ of the wines. As can be seen, 
$h_{\mathrm{ab}}$ decreased gradually with increasing aging time, indicating a higher reddening (angles closer to 0 ) in the older sweet wines. Similarly to the browning results discussed above, the MontillaMoriles D.O. wines did not differ significantly in $h_{\mathrm{ab}}$ after five and ten years of aging (with 59.9 and 64.6, respectively), but the difference between five-year old and unaged wines and between five- and twenty-five-year-old wines (78.0 and 51.03, respectively) was significant. The wines from the Jerez-XérèsSherry D.O. aged for five and ten years showed significant differences in the hue (61.8 vs 44.8), although the results for the latter exhibited a high dispersion (they ranged from 27.9 to 59.9). The lightness results $\left(L^{*}\right.$ ab , which ranges from 0 for black to 100 for white) evolved similarly and revealed progressive darkening in the wines as they aged. Taking into account the parallel evolution during aging of darkening and reddening, the data of $h_{\mathrm{ab}}$ and $L^{*}$ ab for the 84 bottles studied were subjected to linear regression, which revealed both parameters to be linearly related by the equation $h_{\mathrm{ab}}=31.4+0.696 L^{*}{ }_{\mathrm{ab}}\left(R^{2}=94.5 \%, p<\right.$ 0.001 ) irrespective of the wine D.O.

Fig. 7 shows the ranges of variation of the contents in high-molecular weight (HMW) brown polymers, measured as absorbance at $420 \mathrm{~nm}$ in the fraction dialysed from the wines. These compounds can include caramelisation products and high-molecular weight phenolic compounds, although this must be contributed largely by melanoidins because their UV-visible spectrum was very similar to those for synthetic melanoidins reported by other authors (Perez-Magariño et al., 2000). Melanoidins include products of the Maillard reaction that contribute to the browning of wine and its sensory properties. As can be seen, the young wines from the Montilla-Moriles

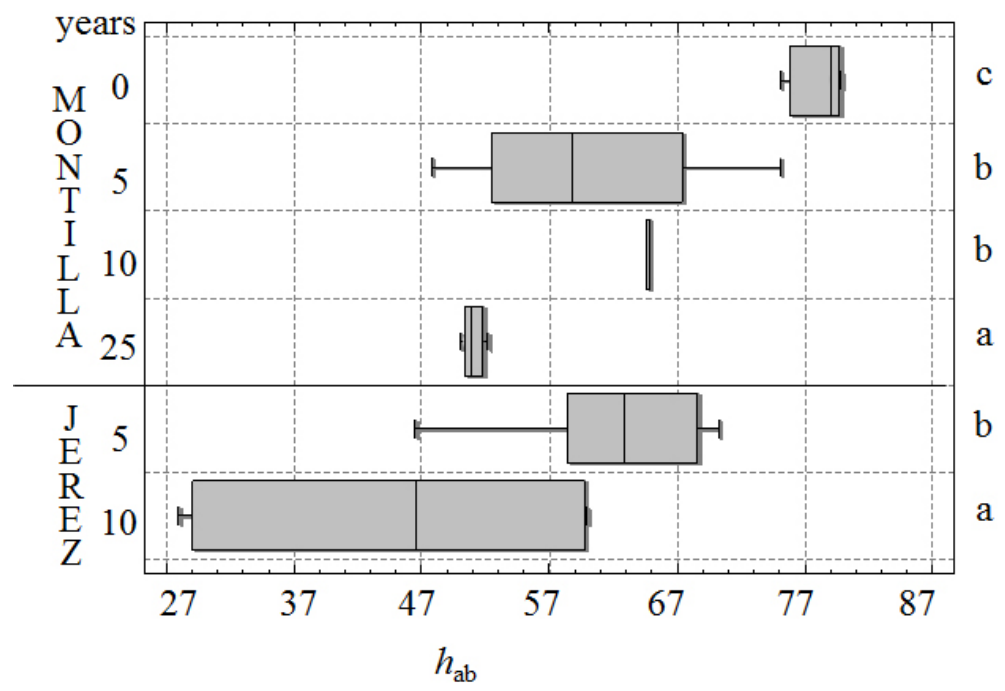

FIGURE 5

Box-and-whisker plot of the hue angle $\left(h_{\mathrm{ab}}\right)$ values in the studied wines and their statistically homogeneous groups.

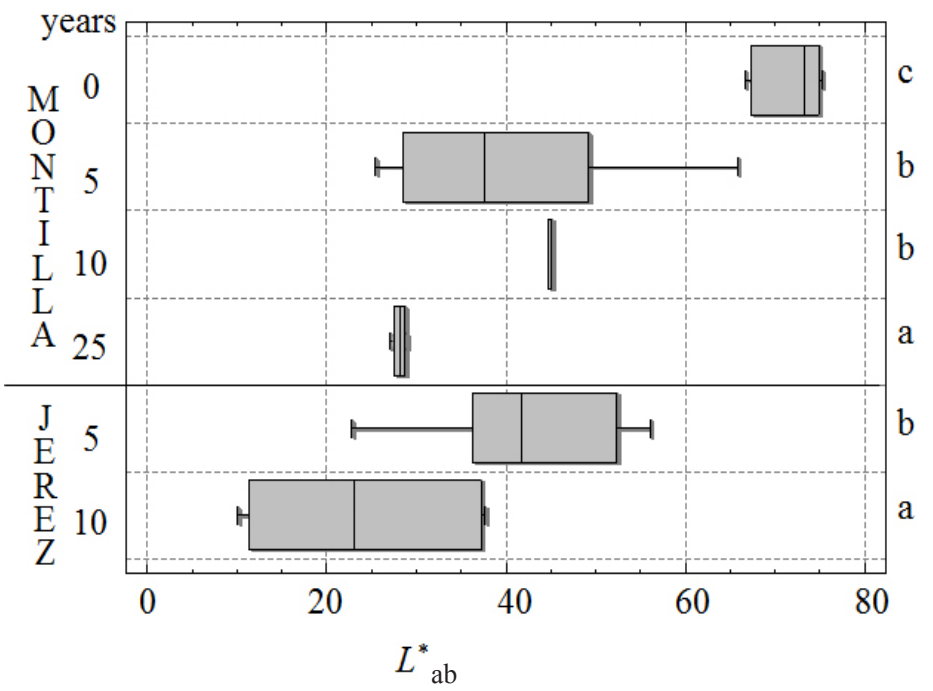

FIGURE 6

Box-and-whisker plot of the lightness $\left(L^{*}{ }_{\mathrm{ab}}\right)$ values in the studied wines and their statistically homogeneous groups. 


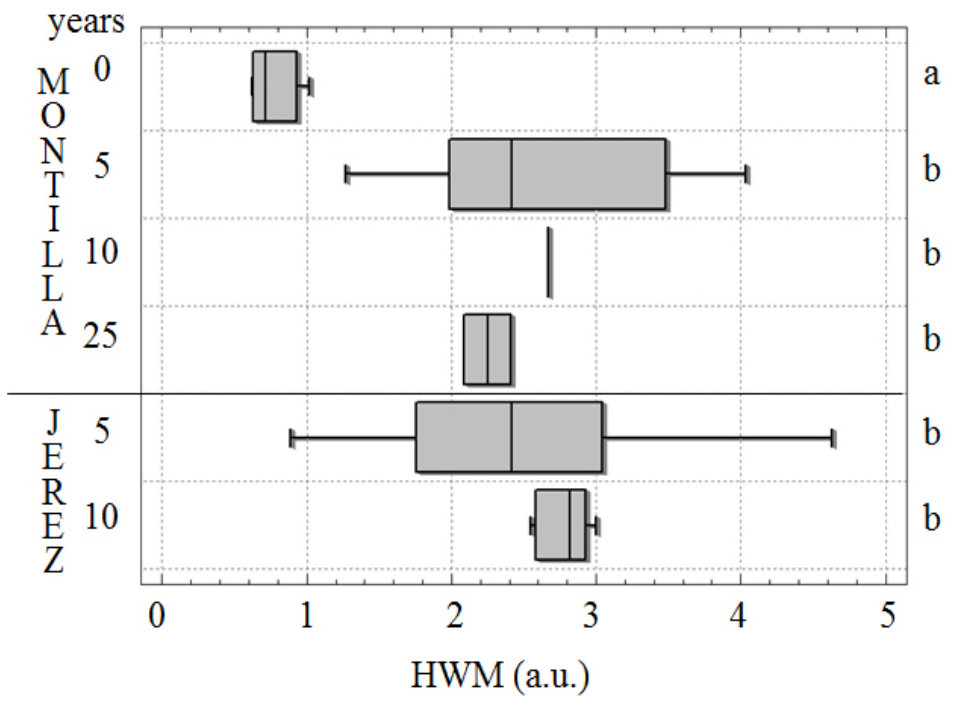

FIGURE 7

Box-and-whisker plot of the absorbance at $420 \mathrm{~nm}$ values (a.u.) corresponding to the high-molecular weight (HMW) brown polymers in the studied wines and their statistically homogeneous groups.

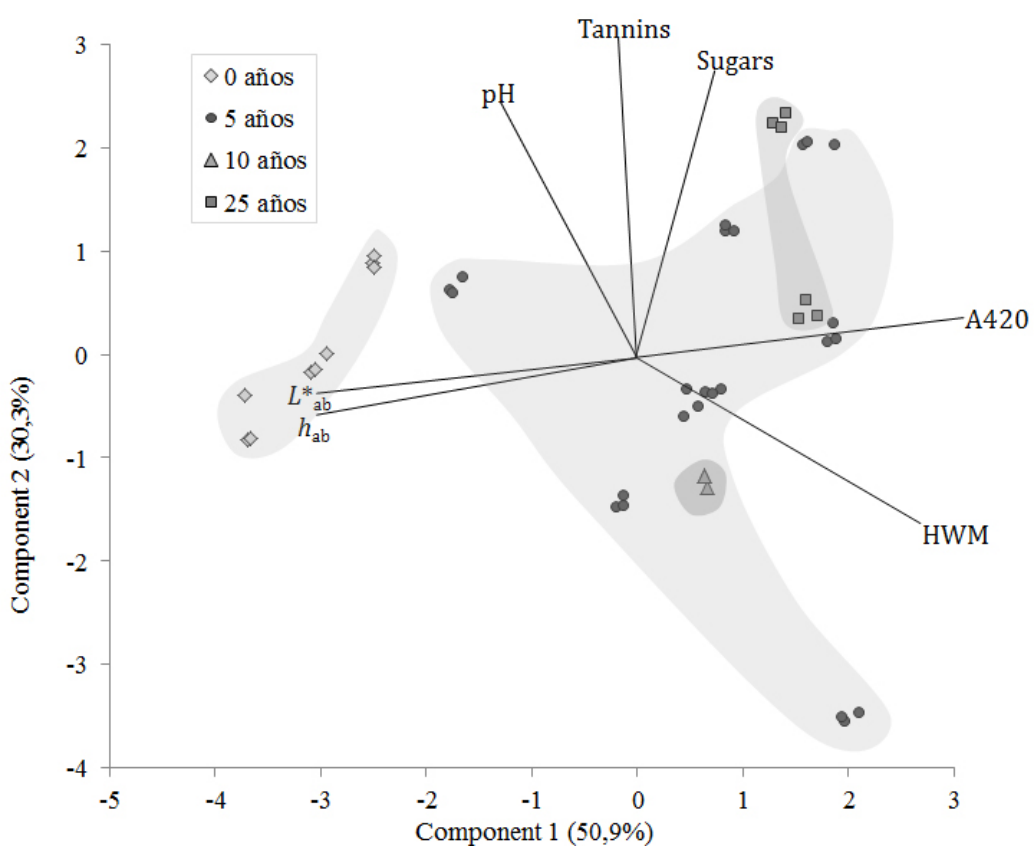

FIGURE 8

Principal components analysis: Biplot representation of variables and scores of the wines from the Montilla-Moriles D.O.

D.O. were those exhibiting the lowest values $(0.767 \mathrm{au})$ in this parameter, with significant differences from all others of this D.O., which formed a homogeneous, albeit highly disperse, group. Thus, the five-year-old wines from the Montilla-Moriles D.O. exhibited absorbances from 1.27 to 4.03 au, and those from the Jerez-Xérès-Sherry D.O. values from 0.891 to $4.63 \mathrm{au}$. On the other hand, the HMW values for the wines were found to be correlated with A420 of their corresponding wines via the exponential equation HMW $=\exp (-1.63+0.762 \times$ A420 $)$ at $p<0.001$. This suggests that colour in the studied wines is influenced by the presence of increasingly brown polymers as A420 increases.

In order to better observe the influence of the different variables measured with the aging time, a multivariate principal component analysis was carried out on the samples of each region studied. Fig. 8 shows the biplot representation of variables and scores of the Montilla-Moriles samples on the plane defined by the first two principal components, which jointly accounted for $81.2 \%$ of the overall variance. Based on the results, lightness, hue, browning index and HWM were the variables with the 


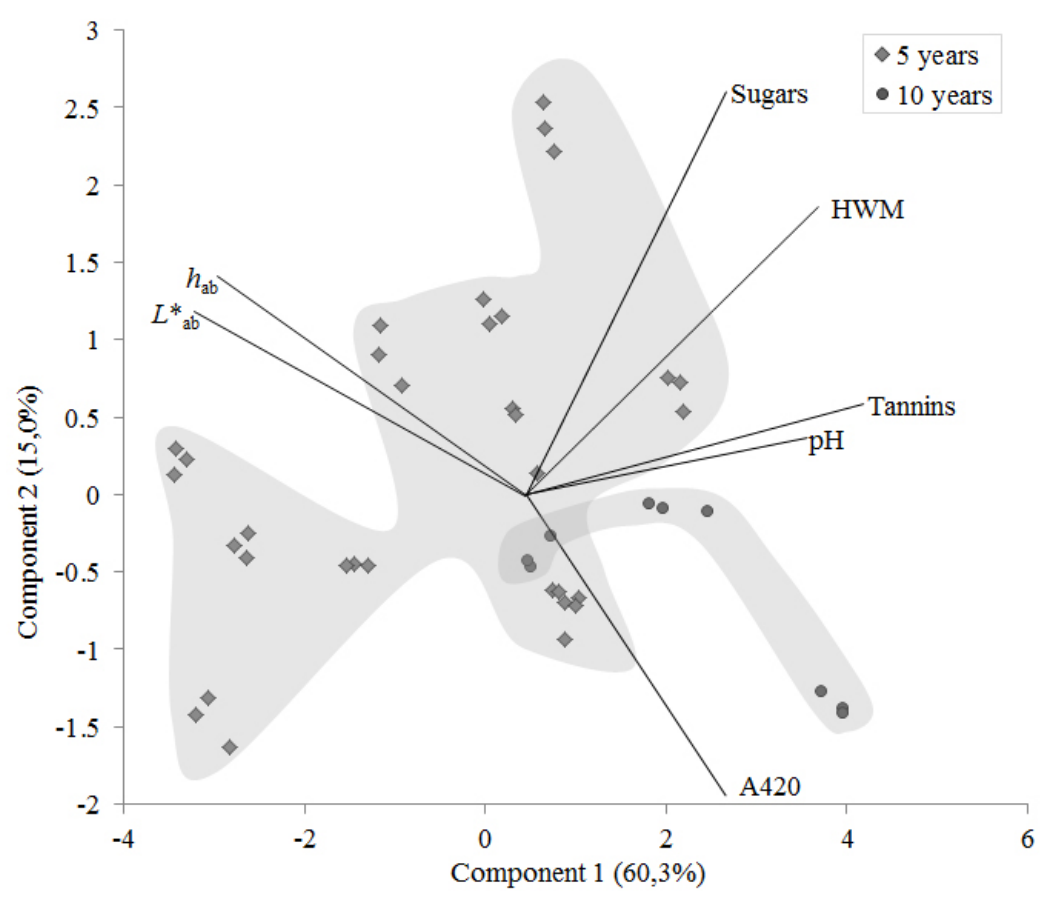

FIGURE 9

Principal components analysis: Biplot representation of variables and scores of the wines from the Jerez-Xérès-Sherry D.O.

highest statistical weights on the PC1, the tannin index, sugars and $\mathrm{pH}$ being those exerting more influence on the PC2. However, except for samples corresponding to the unaged wines, no statistical separation could be clearly observed for the aged wines, mainly as a result of the high dispersion in the data of the wines aged for five years. The samples representing the Jerez region were subjected to Principal Components Analysis (Fig. 9), obtaining two PCs which accounted for $75.3 \%$ of the overall variance. For the wines aged in this region, the variables with highest statistical weights on the PC1 were lightness, tannin index, hue, and $\mathrm{pH}$, sugars, browning index, and HWM being those exerting more influence on the PC2. As can be seen, the samples representing five years' aging also showed a great dispersion, although the wines aged for ten years showed a trend to higher scores on the PC1 than those of five years old.

A discriminant analysis was carried out with a view to identifying the parameters best discriminating the wines according to origin (Montilla-Moriles or Jerez-Xérès-Sherry). The results provided no significant discriminant function with a greater than unity eigenvalue. Therefore, except for an increased alcoholic content in the wines from Jerez-XérèsSherry, the studied Pedro Ximenez sweet wines exhibited no significant differences from the Montilla-Moriles wines in colour characteristics or contents in polyphenols of high or low molecular weight, enabling their unequivocal assignation to either D.O. The greatest differences among the wines occurred as a result of their oxidative aging. However, the specific conditions in each cellar appear to have resulted in large differences in those wine characteristics that are easily perceived by consumers (hue and lightness, mainly). This high dispersion can lead to confusion in identifying the quality of each product since, as noted earlier, wines aged for ten years have colour characteristics similar to those aged for half the time. A better knowledge of the dependence of the usual practices of each winemaker on these parameters is therefore required with a view to facilitating standardisation of the products according to aging time. Such knowledge could be acquired similarly to that previously gathered for other Sherry wine types, such as the so-called "fino" wines. These wines are obtained by means of a more delicate biological aging process which causes their production to be controlled in a more precise manner, particularly in regard to temperature and moisture during aging.

\section{LITERATURE CITED}

Amerine, M.A. \& Winkler, A.J., 1944. Composition and quality of musts and wines of California grapes. Hilgard, 15, 493-673.

C.I.E., 2004 ( $3^{\text {rd }}$ ed). Colourimetry. Publication of the International Commission on Illumination, Vienna, Austria.

Cadahia, E., Muñoz, L., Fernandez de Simon, B. \& Garcia-Vallejo, M.C., 2001. Changes in low molecular weight phenolic compounds in Spanish, French, and American oak woods during natural seasoning and toasting. J. Agric. Food Chem. 49, 1790-1798.

Casas, J.F. Descripción resumida de la técnica enológica de los vinos de Jerez". In: University of Cadiz (ed). Proc. III Jorn. Univ., 1985, Cadiz, España. pp. 333-361.

Chaves, M., Zea, L., Moyano, L. \& Medina, M., 2007. Changes in color and odorant compounds during oxidative aging of Pedro Ximenez sweet wines. J. Agric. Food Chem. 55, 3592-3598.

Clark, A.C. \& Scollary, G.R., 2002. Copper (II)-mediated oxidation of $(+)$-catechin in a model white wine system. Aust. J. Grape Wine Res. 8, 186195 .

Clark, A.C. \& Scollary, G.R., 2003. Influence of light exposure, ethanol and copper (II) on the formation of a precursor for xanthylium cations from tartaric acid. Aust. J. Grape and Wine Res. 9, 64-71. 
Clark, A.C., Prenzler, P.D. \& Scollary, G.R., 2003. The role of copper (II) in the bridging reactions of $(+)$-catechin by glyoxylic acid in a model white wine. $\mathrm{J}$. Agric. Food Chem. 51, 6204-6210.

EEC, 1990. Official report of the European Community. Ed. Mundi-Prensa, Madrid.

Escalona, E., Birkmyre, L. \& Piggott, J.R., 2002. Effect of maturation in small oak casks on the volatility of red wine aroma compounds. Analitica Chimica Acta $458,45-54$

Es-Safi, N.E., Cheynier, V. \& Moutounet, M., 2003. Effect of copper on oxidation of (+)-catechin in a model solution system. Int. J. Food Sci. Technol. $38,153-163$

Es-Safi, N.E., Guerneve, C., Cheynier, V. \& Moutounet, M., 2000. New phenolic compounds formed by evolution of (+)-catechin and glyoxylic acid in hydroalcoholic solution and their implication in color changes of grape-derived foods. J. Agric. Food Chem. 48, 4233-4240.

Fernandez de Simon, B., Conde, E., Cadahía, E. \& García-Vallejo, M.C., 1996. Low-molecular-weight phenolic compounds in woods of Spanish, French and American oak. J. Sci. Technol. Tonnellerie 2, 13-23.

Feuillat, F. \& Keller, R., 1997. Variability of oak wood (Quercus ruber L., Quercus petraea Liebl.) anatomy relating to cask properties. Am. J. Enol. Vitic. $47,502-508$

Fulcrand, H., Doco, T., Es-Safi, N., Cheynier, V. \& Moutonet, M., 1996. Study of the acetaldehyde induced polymerisation of flavan-3-ols by liquid chromatography-ion spray mass spectrometry. J. Chromat. 752, 85-91.

Glories, Y. \& Saucier, C., 2000. Tannin evolution from grape to vine. Effects on wine taste. In: Proc. ASEV 50th Anniversary annual meeting, 2000, Seattle, Washington. pp. $353-355$.

Gomez-Cordoves, C. \& Gonzalez San Jose, M.L., 1995. Interpretation of color variables during the aging of red wines: Relationship with families of phenolic compounds. J. Agric. Food Chem. 43, 557-561.

Gunata, Y., Pineau, J. \& Cordonnier, R., 1987. Détermination de la qualité de la vendage par sa richesse en composés phénoliques. Applications à la vinification. R.F. OE. 187, 7-13.

Kadim, D. \& Mannheim, H., 1999. Kinetics of phenolic extraction during aging of model wine solution and white wine in oak barrels. Am. J. Enol. Vitic. 50, 33-39.

Karadeniz, F., Durst, R.W. \& Wrolstad, R.E., 2000. Polyphenolic composition of raisin. J. Agric. Food Chem. 48, 5343-5350.

Lopez-Toledano, A., Villaño-Valencia, D., Mayen, M., Merida, J. \& Medina, M., 2004. Interaction of yeasts with the products resulting from the condensation reaction between (+)-catechin and acetaldehyde. J. Agric. Food Chem. 52, 2376-2381.
Masson, G., Puech, J.L. \& Moutounet, M. Composition chimique du bois de chêne de tonnelerie. In: O.I.V (ed). Bull. O.I.V., 1996, pp. 635-657.

Merida, J., Lopez-Toledano, A. \& Medina, M., 2006. Influence of aerobic and anaerobic conditions and yeasts on the reaction between (+)-catechin and glyoxylic acid. Eur. Food Res. Technol. 222, 451-457.

Ortega, A.F., Lopez-Toledano, A., Mayen, M., Merida, J. \& Medina, M., 2003. Changes in color and phenolic compounds during oxidative aging of Sherry White wines. J. Food Sci 68 (8), 2461-2468.

Ortega-Heras, M., Gonzalez-Huerta, C., Herrera, P. \& Gonzalez-Sanjose, M.L., 2004. Changes in wine volatile compounds of varietal wines during ageing in wood barrels. Analitica Chimica Acta 513, 341-350.

Oszmianski, J., Sapis, J.C. \& Macheix, J.J., 1985. Changes in grape seed phenols as affected by enzymatic and chemical oxidation in vitro. J. Food Sci. $50,1505-1506$

Perez-Magariño, S., Rivero, M. D. \& Gonzalez-Sanjose M. D., 2000. Melanoidins in brown alcoholic beverages. Czech J. Food Sci. 18, 108-109.

Ramshaw, E.H. \& Hardy, P.J., 1969. Volatile compounds in dried grapes. J. Sci Food Agric. 20, 619-621.

Ribereau-Gayon, P., Glories, Y., Maujean, A. \& Dubourdieu, D., 1998. Traité d'Enologie. 2. Chimie du vin. Stabilisation et traitements. Ed. Dunod, Paris.

Rivero-Perez, M.D., Perez-Magariño, S. \& Gonzalez-San Jose, M.L., 2002. Role of melanoidins in sweet wines. Analitica Chimica Acta 458, 169-175.

Rous, C. \& Alderson, B., 1983. Phenolic extraction curves for white wine aged in French and American oak barrels. Am. J. Enol. Vitic. 34, 211-215.

Saucier, C., Bourgeois, G., Vitry, C., Roux, D. \& Glories, Y., 1997. Characterization of $(+)$-catechin-acetaldehyde polymers: A model for colloidal state of wine polyphenols. J. Agric. Food Chem. 45, 1045-1049.

Serratosa, M.P., Lopez-Toledano, A., Merida, J. \& Medina, M., 2008. Changes in color and phenolic compounds during the raisining of grape cv. Pedro Ximenez. J. Agric. Food Chem. 56, 2810-2816.

Simpson, R.F., 1982. Factors affecting oxidative browning of white wine. Vitis 21, 233-239.

Singleton, V.L., 1987. Oxygen with phenols and related reactions in musts, wines, and model systems: Observations and practical implications. Am. J. Enol. Vitic. 38, 69-77.

Viriot, C., Scalbert, A., Herve du Penhoat, C.L.M. \& Moutounet, M., 1994. Ellagitannins in woods of sessile oak and sweet chestnut dimerization and hydrolysis during woods ageing. Phytochem. 36, 1253-1260. 